\title{
Self-assembled structures of alkanethiols on gold-coated cantilever tips and substrates for atomic force microscopy: Molecular organisation and conditions for reproducible deposition
}

\author{
Dimitrios A. Lamprou ${ }^{\text {a }}$ James R. Smith ${ }^{\text {a }}$, Thomas G. Nevell ${ }^{\text {a }}$, Eugen Barbu ${ }^{\text {a }}$, \\ Colin R. Willis ${ }^{\mathrm{b}}$, John Tsibouklis ${ }^{\mathrm{a}, *}$

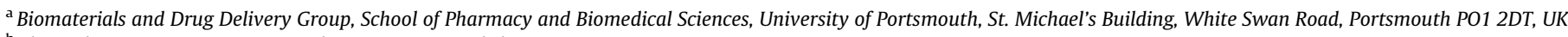 \\ ${ }^{\mathrm{b}}$ Physical Sciences Department, Dstl Porton Down, Salisbury SP4 0JQ UK
}

A R T I C L E I N F O

Article history:

Received 24 July 2009

Received in revised form 2 September 2009

Accepted 15 October 2009

Available online 24 October 2009

\section{Keywords:}

Alkanethiols

Self-assembly

Atomic force microscopy

Infrared spectroscopy

Surface energy

Multilayer deposition

\begin{abstract}
A B S T R A C T
Measurements of surface-liquid interactions (contact-angle goniometry) and tip-surface adhesion forces (atomic force microscopy) combined with infrared spectroscopic studies have been used to investigate surface-preparation and solution-deposition conditions for the reproducible formation of self-assembled molecular structures on gold-coated tips and substrates for atomic force microscopy. Preliminary data show that surface-saturated self-assembled monolayers form reproducibly on prolonged $(>20 \mathrm{~h}$ ) exposure of gold-coated glass substrates to ethanolic solutions of $\omega$-functionalised alkanethiols in the concentration range $80-160 \mathrm{mmol} \mathrm{dm}^{-3}$. The data also show that exposure for $16 \mathrm{~h}$ to alkanethiol concentrations in the range $160-240 \mathrm{mmol} \mathrm{dm}^{-3}$ promote bilayer formation whereas concentrations of $240-320 \mathrm{mmol} \mathrm{dm}^{-3}$ result in the deposition of multilayers, the average orientation of which is parallel to that of the first molecular layer; the use of parent 1-undecanethiol solutions at concentrations of $1-80 \mathrm{mmol} \mathrm{dm}^{-3}$ results in incomplete monolayer coverage.
\end{abstract}

(c) 2009 Elsevier B.V. All rights reserved.

\section{Introduction}

The molecular-level repeating geometric symmetry of alkanethiol-on-gold self-assembled monolayers [1-4] renders such structures ideal model systems for the study of adhesion processes [5]. The successful deposition of alkanethiol SAMs requires the gold substrates to be freshly cleaned by, for example, annealing in a hydrogen-oxygen flame [6], or by exposure to UV/ozone [7-11], or by treatment with a cleaning solution [12-17]. For the deposition of a monolayer, the cleaned substrate is immersed in an ethanolic solution of the thiol, rinsed (ethanol), dried (nitrogen) and used immediately [5]. Concentrations of $0.1-10 \mathrm{mmol} \mathrm{dm}^{-3}$ have been used and exposure/immersion times have ranged from a few minutes to many hours $[13,15,18-26]$. As characterised by contactangle goniometry (CAG), adsorption of alkanethiols from dilute solution onto $\mathrm{Au}\left(\begin{array}{lll}1 & 1 & 1\end{array}\right)$ surfaces occurs via a two-step sequence [1]. A concentration-dependent diffusion-controlled monolayer adsorption (contact angles reached close-to-limiting values over $1 \mathrm{~min}$ at $1 \mathrm{mmol} \mathrm{dm}^{-3}$ or $100 \mathrm{~min}$ at $1 \mu \mathrm{mol} \mathrm{dm}{ }^{-3}$ ) is followed by a slower process in which alkyl chains become more ordered [1].

\footnotetext{
* Corresponding author. Tel.: +44 0 2392842131; fax: +44 02392843565.

E-mail address: john.tsibouklis@port.ac.uk (J. Tsibouklis).
}

Owing to the need to use the same gold-coated cantilever tips and substrates for certain types of atomic force microscopy measurement that demand sequential functionalisation, self-assembled molecular structures of $\omega$-terminal $-\mathrm{OH},-\mathrm{CO}_{2} \mathrm{H},-\mathrm{CH}_{3}$ and $-\mathrm{CF}_{3}$ have been formed on gold-coated glass substrates and on atomic force microscopy (AFM) cantilever tips. CAG [27], AFM [28] and infrared (IR) spectroscopic investigations have been used to characterise the films, to assess their homogeneity and to examine the conditions for the formation of multiply layered molecular structures.

\section{Experimental}

\subsection{Surface preparation}

Gold substrates were formed by cutting gold-coated glass microscope slides (Au.1000.ALSI, gold thickness $100 \mathrm{~nm}$; Platypus Technologies, Madison, WI, USA) into sections $1.25 \mathrm{~cm} \times 1.25 \mathrm{~cm}$. AFM cantilevers, coated with an adhesion layer of chromium $(15 \mathrm{~nm})$ overlaid with gold $(60 \mathrm{~nm})$, were supplied by Veeco Instruments SAS, Dourdan, France. Substrates and tips were cleaned individually, using either Piranha Solution (3:1 concentrated sulphuric acid, 33\% (v/v):30\% hydrogen peroxide) [12] or Gold Surface Cleaning Solution (thiourea $1 \%(\mathrm{w} / \mathrm{v})$ in $10 \%$ aqueous 
sulphuric acid; Sigma-Aldrich, Poole, UK) [17]. Immersion times were, for substrates, $1 \mathrm{~h}$ in Gold Surface Cleaning Solution or $15 \mathrm{~min}$ in Piranha Solution, and for tips, $5 \mathrm{~min}$ in either solution. Cleaned substrates and tips were rinsed (water, Millipore, $16.5 \mathrm{M} \Omega \mathrm{cm}$ ) and dried (nitrogen).

\subsection{Formation of self-assembled monolayers and of multilayers}

Organised molecular layers were deposited from ethanolic solutions $\left(1 \mathrm{mmol} \mathrm{dm}^{-3}\right)$ of thiols 1-undecanethiol (98\%; referred to here as ' $\mathrm{CH}_{3}$-terminated'), 11-mercapto-1-undecanol (97\%, 'OHterminated') and 11-mercaptoundecanoic acid (95\%, ' $\mathrm{CO}_{2} \mathrm{H}$-terminated') from Sigma-Aldrich, Poole, UK, and 3,3,4,4,5,5,6,6,7,7,8,8,9,9,10,10,10-heptadecafluoro-1-decanethiol (' $\mathrm{CF}_{3}$-terminated', $>99 \%$ ) from Fluka, Poole, UK. Immediately after preparation/ cleaning, each gold substrate or AFM probe was immersed in thiol solution (1-32 h), rinsed (ethanol), dried (nitrogen) and placed in a closed polythene box for storage. Surface measurements (CAG, AFM) were commenced ca. $1 \mathrm{~h}$ after deposition.

\subsection{Contact angle and surface energies}

The contact angles $\left(\theta\right.$ at $\left.20^{\circ} \mathrm{C}\right)$ of droplets $(\times 8)$ of diiodomethane ('DM', 99\%, surface tension $\gamma_{l}=50.8 \mathrm{mN} \mathrm{m}^{-1}$ or $\mathrm{mJ} \mathrm{m}^{-2}, 1 \mu \mathrm{L}$ ) and 1,2-ethanediol ('EG', 99.8\%, $\gamma_{l}=48 \mathrm{mN} \mathrm{m}^{-1} ; 1 \mu \mathrm{L}$ ), Sigma-Aldrich, Poole, UK, and water ('DW', filtered, $\gamma_{l}=72.8 \mathrm{mN} \mathrm{m}^{-1} ; 2 \mu \mathrm{L}$ ) placed on horizontal substrates $(\times 2)$ were measured using a goniometer with an enclosed thermostated cell (Kruss G10, Hamburg, Germany). Advancing $\left(\theta_{A}\right)$ and receding $\left(\theta_{R}\right)$ angles $\left( \pm 0.1^{\circ}\right)$ were obtained for both 'left' and 'right' contact angles at 20-30 s after placement of the drop [29]. Surface energies of substrates $\left(\gamma_{s}\right)$ were calculated from the contact angles and the interfacial energies of the three probe liquids from Eqs. (1) and (2) $[30,31]$ using a Visual Basic program (University of Portsmouth).

$\gamma_{s}=\gamma_{s}^{L W}+\gamma_{s}^{A B}=\gamma_{s}^{L W}+2\left(\gamma_{s}^{+} \gamma_{s}^{-}\right)^{1 / 2}$

$\gamma_{l}=\gamma_{l}^{L W}+\gamma_{l}^{A B}=\gamma_{l}^{L W}+2\left(\gamma_{l}^{+} \gamma_{l}^{-}\right)^{1 / 2}$

$\gamma_{l}(1+\cos \theta)=2\left[\left(\gamma_{s}^{L W} \gamma_{l}^{L W}\right)^{1 / 2}+\left(\gamma_{s}^{+} \gamma_{l}^{-}\right)^{1 / 2}+\left(\gamma_{s}^{-} \gamma_{l}^{+}\right)^{1 / 2}\right]$

where superscripts denote components of surface energy: Lifshitzvan der Waals $L W$, acid-base $A B$, Lewis acid $\gamma^{+}$and Lewis base $\gamma^{-}$. (In $\mathrm{mJ} \mathrm{m}^{-2}$, DW: $\gamma_{l}^{L W}=21.8, \gamma_{l}^{+}=\gamma_{l}^{-}=25.5 ; \quad \mathrm{DM}: \quad \gamma_{l}^{L W}=$ 50.8, $\gamma_{l}^{+}=\gamma_{l}^{-}=0$; EG: $\gamma_{l}^{L W}=29, \gamma_{l}^{+}=1.92, \gamma_{l}^{-}=47$.) [32]

\subsection{Fourier-transform infrared spectrometry}

IR experiments were performed using a Nicolet 6700 FTIR spectrometer coupled to a Nicolet Centaur $\mathrm{s}$ FTIR microscope (ThermoScientific, Madison, USA) with transmission, reflection and attenuated total reflectance (ATR) capabilities. The microscope was equipped with a camera, which provided an optical image $(20 \mu \mathrm{m} \times 20 \mu \mathrm{m})$ of the region sampled by IR. Spectra (4000$650 \mathrm{~cm}^{-1} ; 128$ interferograms, $4 \mathrm{~cm}^{-1}$ resolution) were recorded in left $\mu$ scope reflection mode $(\% R)$ using a single element mercury cadmium telluride (MCT/A) detector. Spectra $(n=2$, three different areas) were recorded - immediately after rinsing (ethanol) and drying (nitrogen) - following the withdrawal of each gold-coated glass substrate from the solution of the precursor thiol; goldcoated tips were not examined.

\subsection{Atomic force microscopy}

A MultiMode/NanoScope IV Scanning Probe Microscope (Digital Instruments, Santa Barbara, CA, USA; Veeco software Version 6.11r1) was used for AFM measurements in air (temperature $24^{\circ} \mathrm{C}$, relative humidity $33 \%$ ). The ' $C$ ' and ' $D$ ' $V$-shaped cantilevers ('NPG'; nominal length $\left(l_{\text {nom }}\right)=115 \mu \mathrm{m}$ and $196 \mu \mathrm{m}$, width $\left(w_{\text {nom }}\right)=17 \mu \mathrm{m}$ and $23 \mu \mathrm{m}$, resonant frequency $\left(v_{\text {nom }}\right)=56 \mathrm{kHz}$ and $18 \mathrm{kHz}$, spring constant $\left(k_{\text {nom }}\right)=0.32 \mathrm{~N} \mathrm{~m}^{-1}$ and $0.06 \mathrm{~N} \mathrm{~m}^{-1}$; Veeco Instruments SAS) and the J-scanner (maximum $x y z$ translation $=200 \mu \mathrm{m} \times 200 \mu \mathrm{m} \times 16 \mu \mathrm{m}$ ) were used. The tip radius $(R)$ for each AFM tip was determined by scanning, in contact mode (scan rate $1.03 \mathrm{~Hz}$ ), an etched silicon surface with features sharper than $R$ (TGT01; MikroMasch, San Jose, CA, USA), followed by profile analysis of the 'artefact' image with a Visual Basic program. The laser alignment was unaltered during measurements (deflection sensitivity $54 \pm 6 \mathrm{~nm} \mathrm{~V}^{-1}$ ) and arrays of $10 \times 10$ force curves were produced from three different areas on each surface. All measurements were duplicated on freshly prepared SAMs. From each force curve, the force of adhesion $\left(F_{\mathrm{ad}}\right)$ was obtained using a Visual Basic program. For ForceVolume ${ }^{\circledR}$ imaging in air, arrays of $64 \times 64$ force curves ( 64 points) were obtained using a ' $C$ ' NPG cantilever and were analysed using Veeco software (Versions 5.12r4 and 7.10, respectively).

For evaluating the cantilever force constant $k$, available procedures include the use of dimensional models (Eqs. (3a) and (3b) [33,34], Eqs. (3c)-(3e) [34-36], and Eqs. (4a) and (4b) [3739]) and dynamic-deflection techniques, namely Cleveland's method [37], the thermal noise method [40] and measurement of resonant frequency in air [41].

$k=\frac{E w t^{3}}{4 l^{3}}$ (beam cantilever)

$k=\frac{E w t^{3}}{2 l^{3}}(\mathrm{~V}$-shaped cantilever $)$

$k=\frac{E w t^{3}}{2 l^{3}}\left(1+\frac{b^{2}}{4 l^{2}}\right)^{-2}(\mathrm{~V}$-shaped cantilever $)$

$k=\frac{E w t^{3}}{2 l^{3}}\left(1+\frac{4 w^{3}}{b^{3}}\right)^{-1}(\mathrm{~V}$-shaped cantilever $)$

$k=\frac{E w t^{3}}{2 l^{3}} \cos \theta\left(1+\frac{4 w^{3}}{b^{3}}(3 \cos \theta-2)\right)^{-1}(\mathrm{~V}$-shaped cantilever $)$

$k \approx \frac{2 \pi^{3} w(l v \sqrt{\rho})^{3}}{\sqrt{E}}($ beam cantilever $)$

$k=(512)^{0.5} \pi^{3} M_{e}^{1.5} w \frac{(l \nu \sqrt{\rho})^{3}}{\sqrt{E}}(\mathrm{~V}$-shaped cantilever $)$

Silicon nitride cantilevers: length $l$, width $w$, thickness $t$; Vshape probe width $b$ and opening angle $2 \theta$ (Fig. 1); resonant frequency in air $v$; density $\rho=3000 \mathrm{~kg} \mathrm{~m}^{-3}$, Young's modulus: $E=175 \mathrm{GPa}$ [42]; normalised effective mass $M_{e}=0.163$ [40].

Cleveland's dynamic-deflection method, where a microsphere is attached to the end of a cantilever and the change in resonant frequency is measured, may result in damage to the tip and hence is not the method of choice. The thermal noise method is only suited to beam-shaped cantilevers, although the employment of a correction factor has been suggested for V-shaped cantilevers [43]. For many AFM instruments, however, additional circuitry is required and the accuracy in measuring $k$ is not improved greatly compared with other techniques (15-20\%) [39]. Alternatively, $k$ may be determined by using the AFM to push the cantilever against a reference cantilever $\left(k_{\text {ref }}\right)$ and against a hard surface (silicon), measuring the deflection sensitivities (gradient of the force- 


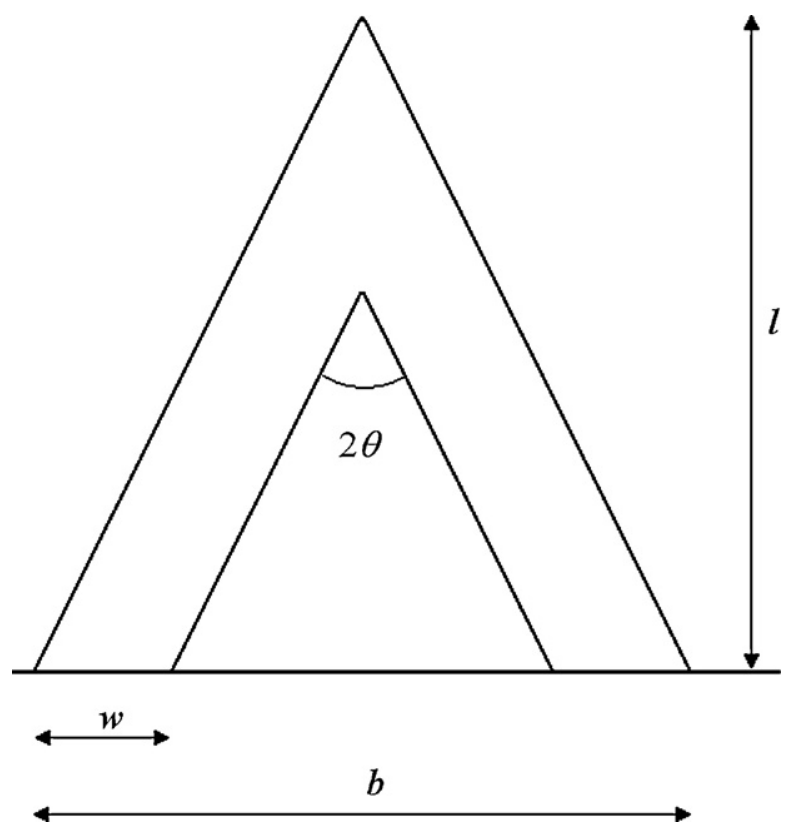

Fig. 1. V-shaped AFM cantilever: length $l$, width $w$, probe base width $b$, opening angle $2 \theta$. distance curve) $S_{\text {ref }}$ and $S_{\text {hard }}[4,40,44]$. The relative merits of these techniques have been reviewed by Clifford and Seah [45].

$k=k_{\text {ref }}\left(\frac{S_{\text {ref }}}{S_{\text {hard }}}-1\right)$

In comparing here these methods of determining $k$, cantilever dimensions were measured by light microscopy ( $l$ and $w$; Olympus 1 X71 inverted microscope) and by scanning electron microscopy $(t, l$ and $w$; JEOL JSM-6060LV, 10 and $25 \mathrm{kV}$, spot size $35 \mu \mathrm{m}$, working distance $12-14 \mathrm{~mm}$ ). The reference cantilever was supplied by Veeco Instruments SAS (Wafer: FC007 Box 31; Model no. CLCFNOBO; part no. 00-103-0994; $l_{\text {nom }}=100 \mu \mathrm{m}, w_{\text {nom }}=13 \mu \mathrm{m}$, $k_{\text {ref }}=0.188 \mathrm{~N} \mathrm{~m}^{-1}$ ).

\section{Results and discussion}

\subsection{Spring constant determinations}

Comparisons of $k$ derived from dimensional models that use $t$ (Eqs. (3b)-(3e)) show that Eq. (3b), the expression that does not require the determination of $b$ or $\theta$, yields values with a narrow distribution and which are in very close agreement with both those from Eqs. (3c)-(3e) and the nominal values reported by the manufacturer (Table 1a). Hence, Eq. (3b) was selected as that which is representative of the dimensional-model approach, and data were compared with results from the dimensional resonant frequency method Eq. (4b) and from the reference-cantilever technique Eq. (5). In our hands, the use of Eq. (4b) was deemed

Table 1

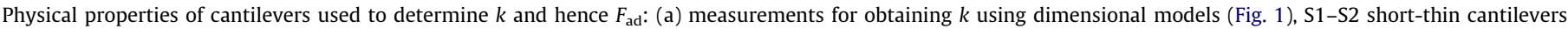

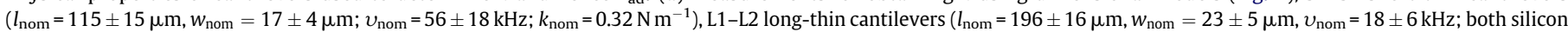

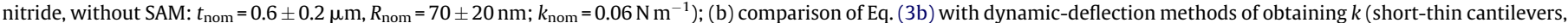
with SAMs); (c) as (b) (long-thin cantilevers, with SAMs).

\begin{tabular}{|c|c|c|c|c|c|c|c|c|c|c|}
\hline \multirow[t]{2}{*}{ Tip } & \multirow[t]{2}{*}{$l / \mu \mathrm{m}$} & \multirow[t]{2}{*}{$w / \mu \mathrm{m}$} & \multirow[t]{2}{*}{$b / \mu \mathrm{m}$} & \multirow[t]{2}{*}{$w / b$} & \multirow[t]{2}{*}{$t / \mu \mathrm{m}$} & \multirow[t]{2}{*}{$2 \theta 1^{\circ}$} & \multicolumn{4}{|l|}{$k / \mathrm{N} \mathrm{m}^{-1}$} \\
\hline & & & & & & & Eq. $\quad(3 b)$ & Eq. $(3 c)$ & Eq. $(3 d)$ & Eq. (3e) \\
\hline \multicolumn{11}{|l|}{ (a) } \\
\hline SD & \pm 0.1 & \pm 0.1 & \pm 0.1 & \pm 0.1 & \pm 0.02 & \pm 0.1 & - & - & - & - \\
\hline $\mathrm{S} 1$ & 98.2 & 17.8 & 105.2 & 0.17 & 0.59 & 53.7 & 0.34 & 0.20 & 0.33 & 0.31 \\
\hline $\mathrm{S} 2$ & 93.4 & 17.6 & 99.6 & 0.18 & 0.57 & 53.1 & 0.35 & 0.21 & 0.34 & 0.32 \\
\hline L1 & 186.8 & 24.9 & 194.1 & 0.13 & 0.56 & 53.0 & 0.06 & 0.04 & 0.06 & 0.05 \\
\hline L2 & 175.4 & 23.9 & 182.6 & 0.13 & 0.59 & 53.2 & 0.08 & 0.05 & 0.08 & 0.07 \\
\hline \multirow[t]{2}{*}{ Tip/SAM } & \multirow[t]{2}{*}{$R / \mathrm{nm}$} & \multirow[t]{2}{*}{$l / \mu \mathrm{m}$} & \multirow[t]{2}{*}{$w / \mu \mathrm{m}$} & \multirow[t]{2}{*}{$t / \mu \mathrm{m}$} & \multirow[t]{2}{*}{$v / \mathrm{kHz}$} & \multirow[t]{2}{*}{$S_{\text {ref }} / \mathrm{nm} \mathrm{V}^{-1}$} & \multirow{2}{*}{$S_{\text {hard }} / \mathrm{nm} \mathrm{V}^{-1}$} & \multicolumn{3}{|l|}{$k / \mathrm{N} \mathrm{m}^{-1}$} \\
\hline & & & & & & & & Eq. (3b) & Eq. (4b) & Eq. (5) \\
\hline \multicolumn{11}{|l|}{ (b) } \\
\hline SD & \pm 1 & \pm 0.1 & \pm 0.1 & \pm 0.02 & \pm 0.5 & \pm 2 & \pm 0.5 & \pm 0.004 & \pm 0.006 & \pm 0.003 \\
\hline S3 & 79 & 117.4 & 17.8 & 0.68 & 43.3 & 149 & 57.0 & 0.303 & 0.042 & 0.297 \\
\hline S4 & 72 & 118.8 & 18.5 & 0.63 & 43.0 & 166 & 53.8 & 0.241 & 0.032 & 0.392 \\
\hline S5 & 64 & 119.5 & 20.6 & 0.57 & 43.2 & 124 & 58.9 & 0.196 & 0.037 & 0.208 \\
\hline S6 & 65 & 113.3 & 17.2 & 0.69 & 43.4 & 124 & 55.4 & 0.340 & 0.027 & 0.233 \\
\hline S7 & 72 & 120.1 & 17.2 & 0.68 & 43.0 & 112 & 49.5 & 0.273 & 0.031 & 0.237 \\
\hline$S 8^{\mathrm{a}}$ & 54 & 106.4 & 18.5 & 0.62 & 48.5 & 143 & 50.0 & 0.320 & 0.034 & 0.350 \\
\hline$S 9^{\mathrm{a}}$ & 51 & 98.2 & 17.8 & 0.61 & 53.5 & 106 & 51.7 & 0.373 & 0.034 & 0.197 \\
\hline \multirow[t]{2}{*}{ Tip/SAM } & \multirow[t]{2}{*}{$R / \mathrm{nm}$} & \multirow[t]{2}{*}{$l / \mu \mathrm{m}$} & \multirow[t]{2}{*}{$w / \mu \mathrm{m}$} & \multirow[t]{2}{*}{$t / \mu \mathrm{m}$} & \multirow[t]{2}{*}{$v / \mathrm{kHz}$} & \multirow[t]{2}{*}{$S_{\text {ref }} / \mathrm{nm} \mathrm{V}^{-1}$} & \multirow[t]{2}{*}{$S_{\text {hard }} / \mathrm{nm} \mathrm{V}^{-1}$} & \multicolumn{3}{|l|}{$k / \mathrm{N} \mathrm{m}^{-1}$} \\
\hline & & & & & & & & Eq. (3b) & Eq. (4b) & Eq. (5) \\
\hline \multicolumn{11}{|l|}{ (c) } \\
\hline SD & \pm 1 & \pm 0.1 & \pm 0.1 & \pm 0.02 & \pm 0.5 & \pm 2 & \pm 0.5 & \pm 0.004 & \pm 0.006 & \pm 0.003 \\
\hline L3 & 66 & 195.0 & 25.4 & 0.64 & 15.6 & 152 & 90.0 & 0.079 & 0.010 & 0.130 \\
\hline L4 & 60 & 195.7 & 26.8 & 0.62 & 15.6 & 190 & 83.5 & 0.075 & 0.011 & 0.240 \\
\hline L5 & 68 & 197.0 & 25.4 & 0.69 & 15.7 & 165 & 77.7 & 0.095 & 0.011 & 0.211 \\
\hline L6 & 50 & 195.7 & 26.8 & 0.63 & 15.6 & 81 & 74.3 & 0.078 & 0.011 & 0.017 \\
\hline L7 & 57 & 201.8 & 26.8 & 0.62 & 15.7 & 166 & 83.2 & 0.068 & 0.012 & 0.187 \\
\hline $\mathrm{L}^{\mathrm{a}}$ & 47 & 188.8 & 24.0 & 0.55 & 17.4 & 154 & 86.6 & 0.052 & 0.012 & 0.146 \\
\hline $\mathrm{L} 9^{\mathrm{a}}$ & 63 & 175.1 & 25.4 & 0.59 & 18.9 & 102 & 88.3 & 0.085 & 0.013 & 0.029 \\
\hline
\end{tabular}

a Probe type NP (silicon nitride, not gold-coated; Veeco Instruments SAS, Dourdan, France), $R_{\mathrm{nom}}=40 \pm 20 \mathrm{~nm}$. 
Table 2

$F_{\text {ad }}$ measurements, in air, between a gold-coated AFM tip and gold-coated glass surfaces cleaned with Gold Surface Cleaning Solution and Piranha Solution $(n=2)$.

\begin{tabular}{lcc}
\hline Au-coated glass surface & \multicolumn{2}{l}{$F_{\text {ad }} / \mathrm{nN}$} \\
\cline { 2 - 3 } & Gold Surface Cleaning & Piranha Solution \\
& Solution & \\
\hline Before cleaning & $50 \pm 2$ & $51 \pm 3$ \\
After cleaning & $18.3 \pm 0.5$ & $18.2 \pm 0.2$ \\
\hline
\end{tabular}

inappropriate since it yielded $k$ values that were between 5 and 8 times smaller than $k_{\text {nom }}$. Similarly, the reference cantilever method (Eq. (5)) was not adopted since for short cantilevers it yielded a range of $k$ values that was broader than that obtained using Eq. (3b), and $k$ determinations for long cantilevers were found to be associated with a very large standard error. For short gold-coated cantilevers with adsorbed SAMs, respective mean percentage errors in $k$ as calculated from Eqs. (3b), (4b) or (5) were 5\%, 89\% and $15 \%$; corresponding values for long cantilevers were $27 \%, 81 \%$ and $129 \%$ (Table $1 \mathrm{~b}$ and c).

\subsection{Cleaning of gold-coated glass substrates}

To assess the capacity of gold-coated surfaces to adsorb thiourea from the Gold Surface Cleaning Solution, $F_{\text {ad }}$ measurements were carried out (AFM tip 'as received' by the manufacturer; tip S3, Table 1b) before and after cleaning with each of the solutions used (Table 2). The after-cleaning values were found to be in very close agreement $(t=0.1699, P=0.8807)$, indicating that thiourea is not adsorbed onto the Au surface. Further confirmation was provided by IR spectroscopy: cleaned gold surfaces did not exhibit any infrared bands that could be attributed to thiourea.

To investigate the capability of the Gold Surface Cleaning Solution to remove SAMs from gold-coated AFM tips, $F_{\mathrm{ad}}$ measurements were recorded for interactions of 'as received' and of cleaned gold-coated AFM tips (S3 and S7; Table 1b) with cleaned gold-coated substrates. Rationalised by the need to maintain chemical specificity [46], these experiments were conducted in air despite the implications associated with possible influences from capillary forces [47]. With an 'as received' tip (S7), $F_{\text {ad }}$ was $56 \pm 1 \mathrm{nN}$ whereas after cleaning this was $24.8 \pm 0.3 \mathrm{nN}$. Following tip functionalisation with the perfluoroalkylthiol $\left(\left[\mathrm{CF}_{3}-\right.\right.$ terminated] $=1 \mathrm{~mol} \mathrm{dm}^{-3}$ in EtOH, $16 \mathrm{~h}$ ), corresponding $F_{\text {ad }}$ values increased to $83.8 \pm 0.1 \mathrm{nN}$. On subsequent cleaning of the functionalised tip ( $5 \mathrm{~min}$ ) the $F_{\mathrm{ad}}$ values returned to $24.6 \pm 0.5 \mathrm{nN}$. Corresponding experiments involving the use of Piranha Solution [48-51] for tip cleaning yielded $F_{\text {ad }}$ values of $53.3 \pm 0.8 \mathrm{nN}$ before cleaning and of $32.9 \pm 0.3 \mathrm{nN}$ after cleaning. Used for imaging, tips cleaned with Piranha Solution were found to be more likely to produce 'double-tip effects' than those cleaned with Gold Surface Cleaning Solution.

The capacities of Gold Surface Cleaning Solution and of Piranha Solution to remove surface contamination and to wash SAMs from gold-coated surfaces were investigated by CAG. Advancing contact angles $\left(\theta_{A}\right)$ of surfaces cleaned with either agent before or after the deposition of a $\mathrm{CF}_{3}$-terminated SAM were similar. For surfaces cleaned with Piranha Solution or with Gold Surface Cleaning Solution respective initial $\theta_{A}$ values of $88 \pm 4^{\circ}$ and $87 \pm 2^{\circ}$ were seen to increase post-deposition of the $\mathrm{CF}_{3}$-terminated SAM to $119 \pm 2^{\circ}$ and to $115 \pm 2^{\circ}$, Table 3 . Significantly, exposure of the SAM-functionalised surfaces to either cleaning solution restored $\theta_{A}$ to the corresponding pre-functionalisation value ( $86 \pm 2^{\circ}$ and $89 \pm 4^{\circ}$ for surfaces cleaned with Piranha Solution and with Gold Surface Cleaning Solution, respectively; $t=1.2761, P=0.2710$ ). Thus, both Gold Surface Cleaning Solution and Piranha Solution are deemed suitable for the removal of SAMs from surfaces. It was found that either cleaning technique could
Table 3

Advancing contact angles, $\theta_{A}$, of gold-coated surfaces before and after cleaning.

\begin{tabular}{lccc}
\hline Au-coated glass surface & $\begin{array}{l}\text { Piranha } \\
\text { Solution }\end{array}$ & \multicolumn{2}{l}{$\theta_{A} /^{\circ}$} \\
\cline { 3 - 4 } Batch $^{\mathrm{a}}$ & $\mathrm{I}$ & \multicolumn{2}{l}{$\begin{array}{l}\text { Gold Surface Cleaning } \\
\text { Solution }\end{array}$} \\
\cline { 3 - 4 } & & $\mathrm{I}$ & $\mathrm{II}$ \\
\hline Initial cleaning $^{\mathrm{b}}$ & - & - & $81 \pm 3$ \\
Initial cleaning $^{\mathrm{c}}$ & $88 \pm 4^{\mathrm{e}}$ & $87 \pm 2^{\mathrm{f}}$ & - \\
Initial cleaning $^{\mathrm{d}}$ & - & - & $80 \pm 2$ \\
$\mathrm{CF}_{3} \mathrm{SAM}^{\mathrm{b}}$ & - & - & $106 \pm 2$ \\
$\mathrm{CF}_{3} \mathrm{SAM}^{\mathrm{c}}$ & $119 \pm 3$ & $115 \pm 2$ & - \\
$\mathrm{CF}_{3} \mathrm{SAM}^{\mathrm{d}}$ & - & - & $112 \pm 2$ \\
$\mathrm{Cleaned}^{\mathrm{b}}$ & - & - & $81 \pm 2$ \\
$\mathrm{Cleanned}^{\mathrm{c}}$ & $89 \pm 4^{\mathrm{e}}$ & $86 \pm 2^{\mathrm{f}}$ & - \\
Cleaned $^{\mathrm{d}}$ & - & - & $80 \pm 3$ \\
\hline
\end{tabular}

a The variation between the Au $\theta_{A}$ values is due to different batches of Au being used; batch I, $n=4$; batch II, $n=2$.

b Surface used for $\left[\mathrm{CF}_{3}\right.$-terminated thiol $]=0.1 \mathrm{mmol} \mathrm{dm}^{-3}$.

c Surface used for $\left[\mathrm{CF}_{3}\right.$-terminated thiol $]=1 \mathrm{mmol} \mathrm{dm}^{-3}$.

d Surface used for $\left[\mathrm{CF}_{3}\right.$-terminated thiol $]=10 \mathrm{mmol} \mathrm{dm}^{-3}$.

e $t=0.3303, P=0.7524$, not statistically significant ( $99 \%$ confidence).

f $t=0.7913, P=0.4589$, not statistically significant (99\% confidence).

be used to regenerate gold-coated glass surfaces for up to five times before the gold became detached from the underlying substrate or the surface became discoloured. The relationship between thiol concentration and resultant $\theta_{A}$ was investigated using gold-coated glass surfaces that had been functionalised with the $\mathrm{CF}_{3}$-terminated SAM $\left(0.1,1,10 \mathrm{mmol} \mathrm{dm}^{-3}\right.$; Table 3$)$; differences in $\theta_{A}$ are attributable to batch variation. Consistent with the complete subsequent removal of SAMs, water contact angles for functionalised $\left(0.1 \mathrm{mmol} \mathrm{dm}^{-3}, 16 \mathrm{~h}\right)$ surfaces that had been treated with Gold Surface Cleaning Solution returned to their values prior to coating (Table 4 ). To assess the capacity of Gold Surface Cleaning Solution to remove probe liquids from the gold-coated substrate, water contact angles were determined for cleaned surfaces that had been immersed successively in DW, DM and EG: in all cases, water contact angles before and after treatments were similar.

To determine the optimum cleaning time, values of $\theta_{A}$ for water on $\mathrm{CF}_{3}$-terminated $\mathrm{SAM}$ surfaces $\left(2 \mathrm{mmol} \mathrm{dm}^{-3}, 16 \mathrm{~h}\right.$ ) were measured after exposure to the Gold Surface Cleaning Solution for specified time periods, and compared with values for similarly treated non-functionalised gold control surfaces (Fig. 2). Within the 5-60 min timescale, contact angles appeared to be independent of cleaning time (for samples and controls, respective $\theta_{A}$ values were restored to $88 \pm 1^{\circ}$ and to $90 \pm 3^{\circ}$ from prefunctionalised values of $86 \pm 2^{\circ}$ and $88 \pm 1^{\circ}$ ) indicating that a $\geq 5$ min exposure to the Gold Surface Cleaning Solution removes this SAM. For $\mathrm{CH}_{3}$-terminated SAMs, detachment from the gold-coated glass substrate was assessed by the comparison of the reflectance IR spectra of the SAM structures with those obtained following treatment ( $60 \mathrm{~min}$ ) with either of the two cleaning solutions under investigation: consistent with the efficient removal of SAMs, spectra of cleaned surfaces exhibited none of the features of 1-undecanethiol.

\subsection{Molecular layer formation}

To determine the time required for optimal SAM coverage, $\theta_{R}$ was monitored for gold-coated surfaces that had been exposed to precursor thiol solutions $\left(1 \mathrm{mmol} \mathrm{dm}{ }^{-3}\right.$ ) for specified time periods ranging from $1 \mathrm{~h}$ to $32 \mathrm{~h}$ (Table 5 ). For initially clean gold-coated surfaces without SAMs, the observed time dependence of surface energies determined by CAG reflects the progressive adsorption of atmospheric carbonaceous contaminants [52]. Surface energy values (CAG) for SAMs corresponded with expectation on the basis of the chemical nature of the $\omega$-terminal groups: $\mathrm{OH}>\mathrm{CO}_{2} \mathrm{H}>\mathrm{CH}_{3}>\mathrm{CF}_{3}[3,4,53]$. Consideration of the tabulated 
Table 4

Water contact angles $\left(\theta_{A}\right)$ on gold-coated glass surfaces following SAM and CAG probe liquid removal using Gold Surface Cleaning Solution ( $n=1$ ).

\begin{tabular}{|c|c|c|c|c|}
\hline & \multicolumn{4}{|l|}{$\left.\theta_{A}\right|^{\circ} \mathrm{SAM}$} \\
\hline & OH-terminated & $\mathrm{CO}_{2} \mathrm{H}$-terminated & $\mathrm{CH}_{3}$-terminated & $\mathrm{CF}_{3}$-terminated \\
\hline Initial cleaning & $84 \pm 2$ & $81 \pm 2$ & $82 \pm 2$ & $81 \pm 3$ \\
\hline Cleaning after DW test & $84 \pm 2$ & $81 \pm 2$ & $82 \pm 2$ & $81 \pm 2$ \\
\hline Cleaning after DM test & $84 \pm 1$ & $81 \pm 3$ & $82 \pm 2$ & $81 \pm 4$ \\
\hline Cleaning after EG test & $84 \pm 2$ & $80 \pm 2$ & $83 \pm 2$ & $81 \pm 2$ \\
\hline
\end{tabular}

aFabricated from [thiol $]=0.1 \mathrm{mmol} \mathrm{dm}^{-3}$.

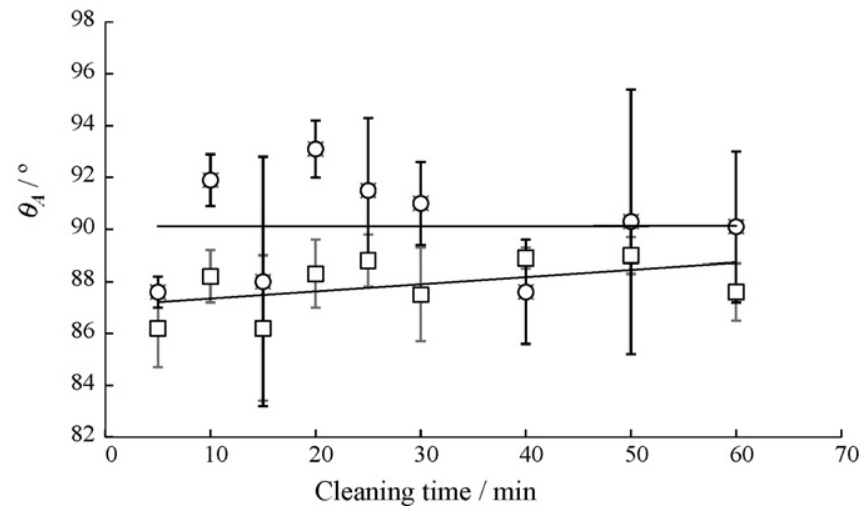

Fig. 2. Advancing water contact angles $\left(\theta_{A}\right)$ of $\mathrm{CF}_{3}$-terminated $\mathrm{SAM}$ (parent-thiol at $2 \mathrm{mmol} \mathrm{dm}^{-3} ; 16 \mathrm{~h}, n=1$ ) grown on gold-coated glass surfaces after exposure to Gold Surface Cleaning Solution for specified times: $(\square)$ initial cleaning (prior to deposition of $\mathrm{CF}_{3}$-terminated $\mathrm{SAM}$ ) and $(\mathrm{O})$ after removal of $\mathrm{CF}_{3}$-terminated SAM.

data for the non-hydrophilic SAMs structures $\left(\mathrm{CH}_{3}\right.$-terminated and $\mathrm{CF}_{3}$-terminated) emphasises the sensitivity of the SAM-formation process to the time of exposure to the thiol solution and highlights the importance of prolonged exposure $(>20 \mathrm{~h}$ ) for the formation of tightly packed SAM structures.

Monitored as a function of time of exposure (16-24 h) to the parent-thiol solution, as with goniometry, the $F_{\text {ad }}$ values $(16-20 \mathrm{~h}$ ) characterising the interaction between a gold-coated AFM tip (S3; Table $1 \mathrm{~b}$ ) and each of the SAMs also reflected the nature of the $\omega$ terminal group functionality: $\mathrm{OH}>\mathrm{CO}_{2} \mathrm{H}>\mathrm{CH}_{3}>\mathrm{CF}_{3}$ (Fig. 3). After exposure for $24 \mathrm{~h}$, however, values of $F_{\text {ad }}$ for the $\mathrm{CH}_{3}$ terminated SAMs corresponded with those for polar-terminated SAMs while that for the $\mathrm{CF}_{3}$-terminated SAM was higher by $c a .30 \%$. These results may be related to the effects of the capillary water columns that may form between the tip and the substrate [54].

To investigate the possible impact of parent-thiol concentration on the free energy of resultant functionalised surfaces, SAMs were deposited (gold-coated glass, $16 \mathrm{~h}$ exposure) from corresponding thiol solutions at specified concentrations (Fig. 4). With the exception of the $\mathrm{CH}_{3}$-terminated SAMs, which exhibited an anomalous behaviour at low parent-thiol concentrations

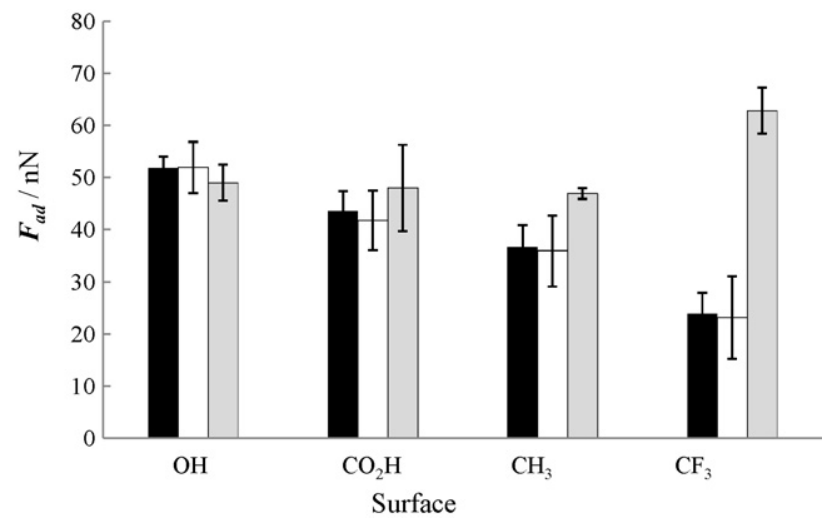

Fig. 3. $F_{\text {ad }}$ values for the interaction between a gold-coated AFM tip and each SAM (air; $n=2$ ) as a function of time of immersion of the gold-coated glass substrate in the parent-thiol solution: $16 \mathrm{~h}$ (black), $20 \mathrm{~h}$ (white), $24 \mathrm{~h}$ (grey); the same tip was used for all measurements (S/Au, Table $1 \mathrm{~b}$ ).

$\left(<1 \mathrm{mmol} \mathrm{dm}^{-3}\right)$, no such effects could be identified. This suggests that the self-assembly process is not concentrationdependent for gold substrates that are allowed to interact with the thiol solution over the $16 \mathrm{~h}$ timescale. For all SAMs under consideration, however, this was contradicted by data from ForceVolume ${ }^{\circledR}$ imaging; this procedure allows the assessment of surface homogeneity by comparing $F_{\text {ad }}$ data from neighbouring points over a specified area of sample. Data from SAM structures deposited from $1 \mathrm{mmol} \mathrm{dm}^{-3}$ solution over $16 \mathrm{~h}$ and sampled against a gold-coated tip indicated that monolayer formation was not complete, since the standard deviations associated with the measurement of $F_{\text {ad }}$ values were considerable: corresponding values for SAMs terminated with $\mathrm{CH}_{3}, \mathrm{CF}_{3}, \mathrm{CO}_{2} \mathrm{H}$, and $\mathrm{OH}$ were $11 \pm 1 \mathrm{nN}, 25 \pm 2 \mathrm{nN}, 31 \pm 2 \mathrm{nN}$ and $33 \pm 10 \mathrm{nN}$.

Infrared spectroscopy provided a further means of assessing the anomalous behaviour of the $\mathrm{CH}_{3}$-terminated SAM. ReflectionAbsorption IR Spectra of $\mathrm{CH}_{3}$-terminated SAMs (Fig. 5) were characterised by the antisymmetric stretch of the terminal $\mathrm{CH}_{3}$ group $\left(2958 \mathrm{~cm}^{-1}\right)$ and by the antisymmetric $2920 \mathrm{~cm}^{-1}$ and symmetric $2850 \mathrm{~cm}^{-1}$ stretching vibrations of the $\mathrm{CH}_{2}$ chain. The weak S-H stretch (2600-2500 $\mathrm{cm}^{-1}$ for pure 1-undecanethiol) was

Table 5

Surface energies $(\gamma)$ of SAMs grown on gold-coated glass surfaces from alkanethiol solutions for different exposure time periods $(n=2)$.

\begin{tabular}{|c|c|c|c|c|c|}
\hline \multicolumn{6}{|c|}{ Surface energy $(\gamma) / \mathrm{mJ} \mathrm{m}^{-2}$} \\
\hline \multirow[t]{2}{*}{ Exposure time/h } & \multicolumn{5}{|l|}{ SAM } \\
\hline & $\mathrm{Au}$ & OH-terminated & $\mathrm{CO}_{2} \mathrm{H}$-terminated & $\mathrm{CH}_{3}$-terminated & $\mathrm{CF}_{3}$-terminated \\
\hline 1 & $39 \pm 3$ & $46 \pm 2$ & $47 \pm 3$ & $50 \pm 2$ & $25 \pm 4$ \\
\hline 2 & $38 \pm 2$ & $45 \pm 1$ & $50 \pm 3$ & $47 \pm 3$ & $22 \pm 2$ \\
\hline 4 & $44 \pm 2$ & $46 \pm 2$ & $48 \pm 2$ & $40 \pm 3$ & $24 \pm 1$ \\
\hline 8 & $39 \pm 2$ & $36 \pm 4$ & $42 \pm 4$ & $34 \pm 1$ & $21 \pm 1$ \\
\hline 16 & $33 \pm 3$ & $44 \pm 3$ & $41 \pm 3$ & $26 \pm 2$ & $15 \pm 2$ \\
\hline 20 & $44 \pm 2$ & $42 \pm 1$ & $35 \pm 3$ & $31 \pm 1$ & $16 \pm 1$ \\
\hline 24 & $39 \pm 3$ & $33 \pm 1$ & $30 \pm 2$ & $26 \pm 3$ & $12 \pm 1$ \\
\hline 32 & $38 \pm 2$ & $29 \pm 1$ & $34 \pm 2$ & $27 \pm 2$ & $11 \pm 2$ \\
\hline
\end{tabular}




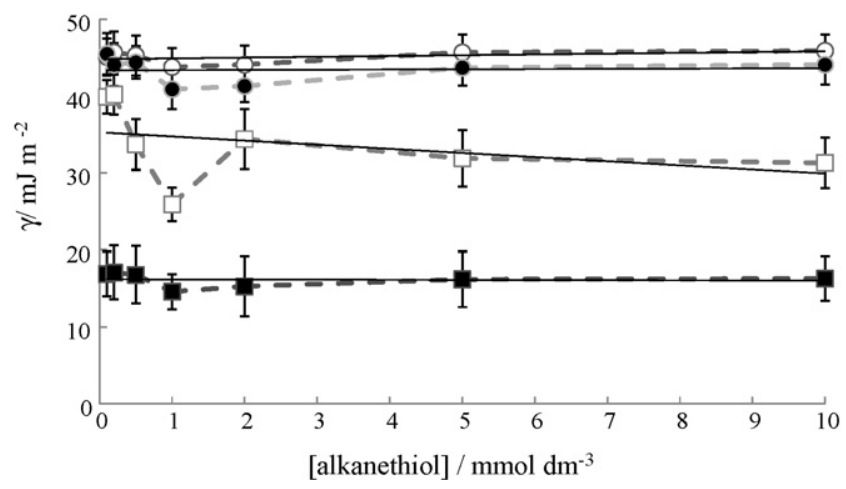

Fig. 4. Surface energies $(\gamma)$ of SAMs grown on gold-coated glass substrates from corresponding alkanethiol solutions $(16 \mathrm{~h}, n=1)$ : $(\mathrm{O}) \mathrm{OH}$-terminated, $(\bullet) \mathrm{CO}_{2} \mathrm{H}$ terminated, $(\square) \mathrm{CH}_{3}$-terminated, and $(\boldsymbol{\square}) \mathrm{CF}_{3}$-terminated.

not detectable in any of the SAM structures, in accord with the deprotonation of the parent-thiol molecule on formation of the S$\mathrm{Au}$ bond. Also, SAM structures did not display the absorptions associated with the $\mathrm{CH}_{2}$ scissoring band $\left(1458 \mathrm{~cm}^{-1}\right)$, the $\mathrm{CH}_{2}$ bending vibration $\left(1372 \mathrm{~cm}^{-1}\right)$, the $\mathrm{CH}_{2}$ wagging mode $\left(1268 \mathrm{~cm}^{-1}\right)$, or the alkyl-chain rocking action $\left(718 \mathrm{~cm}^{-1}\right)$ of 1 undecanethiol, presumably because of the low intensities of these bands relative to those of the alkyl stretches.

To assess the effect of thiol concentration on the quality of the deposited monolayer gold-coated glass substrates were exposed to a series of 1-undecanethiol solutions, each at a specified concentration in the range $0.1-320 \mathrm{mmol} \mathrm{dm}^{-3}$. Consistent with the anomalous data from surface energy determinations (Fig. 4), infrared experiments ((RAIRS, non-polarised light, $86^{\circ}$ angle of incidence) on gold-coated glass surfaces exposed for $16 \mathrm{~h}$ to 1 undecanethiol at concentrations $<1 \mathrm{mmol} \mathrm{dm}^{-3}$ failed to detect this material at the surface, providing further evidence that the successful formation of this SAM requires higher 1-undecanethiol concentrations or longer exposure times. Since the area occupied by each 1-undecanethiol molecule positioned vertical to the surface is approximately $27 \AA^{2}$ [55], each $1 \mathrm{~cm}^{2}$ gold-coated substrate may accommodate up to $\mathrm{ca} .4 \times 10^{14}$ molecules. Even considering the possibility of some thiol adsorption onto glassware, the number of 1-undecanethiol molecules that are available from $10 \mathrm{~cm}^{3}$ of the $1 \mathrm{mmol} \mathrm{dm}{ }^{-3}$ ethanolic thiol solution $\left(6 \times 10^{18}\right.$ molecules) is sufficient to allow the formation of a complete SAM, suggesting that incubation periods necessary for the formation of complete SAMs is related to the dependence of the rate of each chemisorption reaction to parent-thiol concentration.

Infrared microscopy in reflectance mode (angle of incidence $=45^{\circ}$ ) showed that the intensity of the $\mathrm{CH}_{2}$ and $\mathrm{CH}_{3}$ stretching vibrations of structures deposited from 1-undecanethiol solutions in the concentration range $1-80 \mathrm{mmol} \mathrm{dm}^{-3}$ increases with increasing concentration, suggesting incomplete monolayer coverage (Fig. 5). At 1-undecanethiol concentrations between $80 \mathrm{mmol} \mathrm{dm}^{-3}$ and $160 \mathrm{mmol} \mathrm{dm}^{-3}$ the intensity of the detectable infrared absorption appears to be little influenced by the concentration of the parent-thiol, consistent with the formation of a surface saturated monolayer. The spectra of SAMs deposited at 1-undecanethiol concentrations $>160 \mathrm{mmol} \mathrm{dm}^{-3}$ exhibit features that are consistent with multiple layer formation, namely: the antisymmetric $\mathrm{CH}_{3}$ stretch $\left(2958 \mathrm{~cm}^{-1}\right)$ becomes progressively more pronounced; the previously undetected symmetric $\mathrm{CH}_{3}$ stretch emerges at $2905 \mathrm{~cm}^{-1}$; the emerging SH bending mode $\left(863 \mathrm{~cm}^{-1}\right)$ provides evidence that not all sulphur atoms bond directly onto the gold substrate; and a series of new bands appear in the $750-1260 \mathrm{~cm}^{-1}$ region $\left(\mathrm{CH}_{2}\right.$ twisting, $1259 \mathrm{~cm}^{-1} ; \mathrm{CH}_{3}$ rocking, $1092 \mathrm{~cm}^{-1}$; CC stretching, $1016 \mathrm{~cm}^{-1} ; \mathrm{CH}_{2}$ rocking, $796 \mathrm{~cm}^{-1}$; it is assumed that all these signals are augmented to varying degrees as a consequence of the effects of the metalsurface selection rule, which explains the amplification of the components of average transition dipole moments that lie

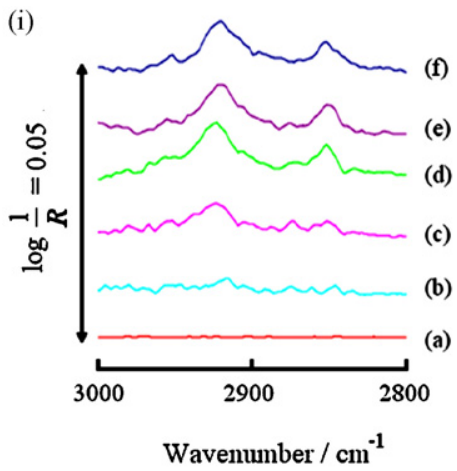

(iii)

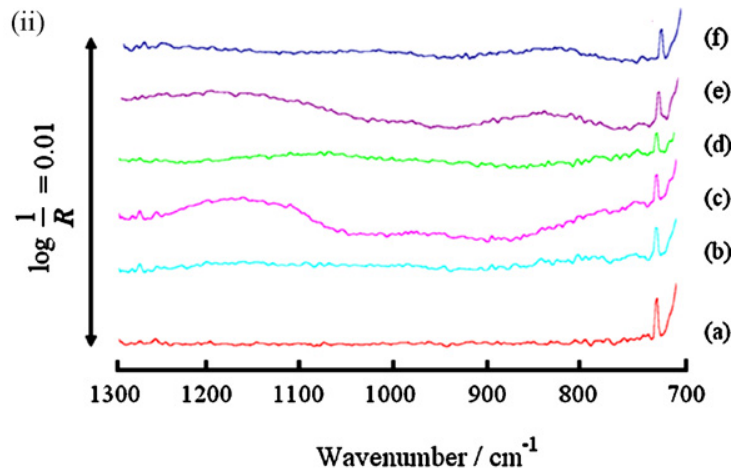

(iv)

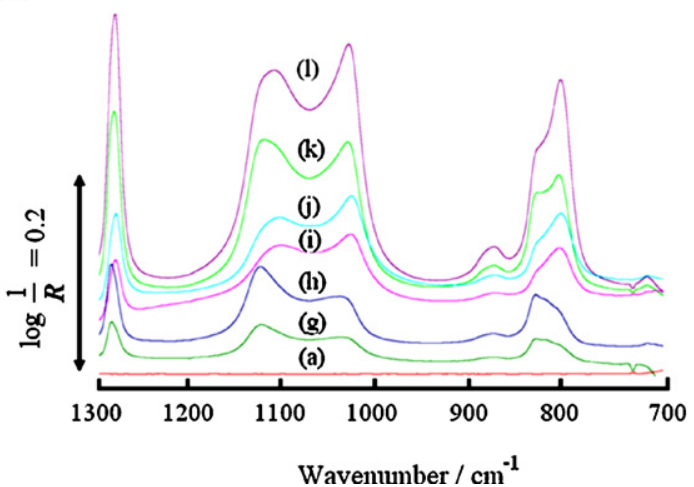

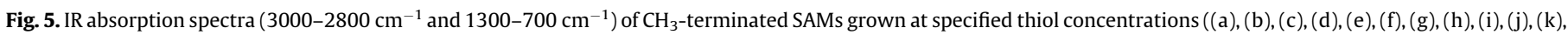
(l): $\mathrm{Au}, 5,10,20,40,80,120,160,200,240,280$ and $320 \mathrm{mmol} \mathrm{dm}^{-3}$ ); spectra are offset for clarity. 
perpendicular to metallic surfaces). Since for deposition in the 1undecanethiol concentration range of $160-240 \mathrm{mmol} \mathrm{dm}^{-3}$ the intensity of these bands does not appear to change noticeably with increasing concentration, it may be assumed that these concentrations promote bilayer formation. The marked increase in the intensity of the same bands at 1-undecanethiol concentrations $>240 \mathrm{mmol} \mathrm{dm}^{-3}$ may be indicative of multilayer formation. Assuming that the $\mathrm{sp}^{3}$ carbon chains are organised in an extended configuration, the average direction of the chains should be perpendicular to the average transition dipole moments of $v_{s}\left(\mathrm{CH}_{2}\right)$, $v_{a s}\left(\mathrm{CH}_{2}\right), \delta\left(\mathrm{CH}_{2}\right)$ and $r\left(\mathrm{CH}_{2}\right)$ [56-58]. Since the relative intensities of these bands remain unchanged, it may be assumed that the multilayer orientation is parallel to that of the first molecular layer.

\section{Conclusions}

The fabrication of homogeneous self-assembled molecular structures on reused gold-coated AFM tips and substrates is sensitive to exposure time to the parent-thiol solution and to its concentration. There is considerable evidence to suggest that low concentrations of the thiol precursor result in the formation of monolayer structures whereas high concentrations promote the formation of multiply layered parallel structures.

\section{Acknowledgement}

We thank the Institute of Biomedical and Biomolecular Sciences (IBBS), University of Portsmouth for providing a studentship to DL.

\section{References}

[1] C.D. Bain, E.B. Troughton, Y.T. Tao, J. Evall, G.M. Whitesides, R.G. Nuzzo, Formation of monolayer films by the spontaneous assembly of organic thiols from solution onto gold, J. Am. Chem. Soc. 111 (1989) 321-335.

[2] U. Jonas, A. del Campo, C. Krüger, G. Glasser, D. Boos, Colloidal assemblies on patterned silane layers, Proc. Natl. Acad. Sci. (USA) 99 (2002) 5034-5039.

[3] A. Niklewski, W. Azzam, T. Strunskus, R. Fischer, C. Woull, Fabrication of selfassembled monolayers exhibiting a thiol-terminated surface, Langmuir 20 (2004) 8620-8924.

[4] G. Jing, J. Ma, D. Yu, Calibration of the spring constant of AFM cantilever, J. Electron. Microsc. 56 (2007) 21-25.

[5] A. Ulman, Formation and structure of self-assembled monolayers, Chem. Rev. 96 (1996) 1533-1544.

[6] M.J. Campina, A. Martins, F. Silva, A new cleaning methodology for efficient AuSAM removal, Electrochem. Acta 53 (2008) 7621-7689.

[7] J. Vig, J. LeBus, UV/ozone cleaning of surfaces, Trans. Parts Hydrids Packaging 12 (1976) 365-370.

[8] C. Schoenenberger, J.A.M. Sondag-Huethorst, J. Jorritsma, L.G.J. Fokkink, What are the "holes" in self-assembled monolayers of alkanethiols on gold? Langmuir 10 (1994) 611-614.

[9] T. Ishida, S. Tsuneda, N. Nishida, M. Hara, H. Sasabe, W. Knoll, High resolution Xray photoelectron spectroscopy measurements of octadecanethiol self-assembled monolayers on $\mathrm{Au}(111$ ), Langmuir 13 (1997) 4638-4643.

[10] H. Ron, S. Matlis, I. Rubinstein, Self-assembled monolayers on oxidized metals. 2. Gold surface oxidative pretreatment, monolayer properties, and depression formation, Langmuir 14 (1998) 1116-1121.

[11] R.F. Dou, X.C. Ma, L. Xi, H.L. Yip, K.Y. Wong, W.M. Lau, J.F. Jia, Q.K. Xue, W.S. Yang, H. Ma, A.K.Y. Jen, Self-assembled monolayers of aromatic thiols stabilized by parallel-displaced $\pi-\pi$ stacking interactions, Langmuir 22 (2006) 3049-3056.

[12] A.S. Duwez, C. Poleunis, P. Bertrand, B. Nysten, Chemical recognition of antioxidants and UV-light stabilizers at the surface of polypropylene: atomic force microscopy with chemically modified tips, Langmuir 17 (2001) 6351-6357.

[13] T. Meng-Yen, L. Jui-Che, Preconditioning gold substrates influence organothiol self-assembled monolayer (SAM) formation, J. Colloid Interface Sci. 238 (2001) 259-266.

[14] H.S. Ahn, P.D. Cuong, S. Park, Y.W. Kim, J.C. Lim, Effect of molecular structure of self-assembled monolayers on their tribological behaviors in nano- and microscales, Wear 255 (2003) 819-825.

[15] A.L. Morales-Cruz, R. Tremont, R. Martinez, R. Romanach, C.R. Cabrera, Atomic force measurements of 16-mercaptohexadecanoic acid and its salt with $\mathrm{CH} 3, \mathrm{OH}$, and $\mathrm{CONHCH} 3$ functionalized self-assembled monolayers, Appl. Surf. Sci. 241 (2005) 371-383.

[16] J. Kang, P.A. Rowntree, Gold film surface preparation for self-assembled monolayers studies, Langmuir 23 (2007) 509-516.

[17] G.K. Parker, G.A. Hope, Spectroelectrochemical investigations of gold leaching in thiourea media, Miner. Eng. 21 (2008) 489-500.
[18] G.M. Whitesides, P.E. Laibinis, Wet chemical approaches to the characterization of organic surfaces: self-assembled monolayers, wetting and the physical-organic chemistry of the solid-liquid interface, Langmuir 6 (1989) 87-96.

[19] P.A DiMilla, J.P. Folkers, H.A. Biebuyck, R. Harter, G.P. Lopez, G.M. Whitesides, J. Wetting and protein adsorption of self-assembled monolayers of alkanethiolates supported on transparent films of gold, J. Am. Chem. Soc. 116 (1994) 2225-2226.

[20] H.I. Kim, T. Koini, T.R. Lee, S.S. Perry, Systematic studies of the frictional properties of fluorinated monolayers with atomic force microscopy: comparison of CF3- and CH3-terminated films, Langmuir 13 (1997) 7192-7196.

[21] A. Amirfazli, D.Y. Kwok, J. Gaydos, A.W. Neumann, Line tension measurements through drop size dependence of contact angles, J. Colloid Interface Sci. 205 (1998) 1-11.

[22] M. Graupe, T. Koini, H.I. Kim, N. Garg, Y.F. Miura, M. Takenaga, S.S. Perry, T.R. Lee, Self-assembled monolayers of CF3-terminated alkanethiols on gold, Coll. Surf. A: Physicochem. Eng. Aspects 154 (1999) 239-244.

[23] Y. Okabe, U. Akiba, M. Fujihira, Chemical force microscopy of $\mathrm{CH} 3$ and $\mathrm{COOH}$ terminal groups in mixed self-assembled monolayers by pulsed-force-mode atomic force microscopy, Appl. Surf. Sci. 157 (2000) 398-404.

[24] H. Awada, G. Castelein, M. Brogly, Quantitative determination of surface energy using atomic force microscopy: the case of hydrophobic/hydrophobic contact and hydrophilic/hydrophilic contact, Surf. Interface Anal. 37 (2005) 755-764.

[25] B. Berron, G.K. Jennings, Loosely packed hydroxyl-terminated SAMs on gold, Langmuir 22 (2006) 7235-7240.

[26] A. Tlili, A. Abdelghani, K. Aguir, M. Gillet, R.N. Jaffrezic-Renault, Adsorption characteristics of self-assembled thiol and dithiol layer on gold, Mater. Sci. Eng. C 27 (2007) 620-624.

[27] A.E. Neumann, R.J. Good, Techniques of measuring contact angles, J. Surf. Colloid Sci. 11 (1979) 31-91.

[28] G. Binning, G.F. Quate, C. Gerber, Atomic force microscope, Phys. Rev. Lett. 56 (1986) 930-933.

[29] A.W. Adamson, A.P. Gast, Physical Chemistry of Surfaces, sixth ed., WileyInterscience, New York, 1997.

[30] W. Zisman, Equilibrium contact angle, Adv. Chem. Ser. (1963) 1-51.

[31] J. Long, M. Hyder, R. Huang, P. Chen, Thermodynamic modelling of contact angles on rough, heterogeneous surfaces, Adv. Colloid Interface Sci. 118 (2005) 173-190.

[32] B. Janczuk, T. Bialopiotrowicz, A. Zdziennicka, Some remarks on the components of the liquid surface free energy, J. Colloid Interface Energy 221 (1999) 96-103.

[33] W.C. Young, R. Budynas, Roark's Formulas for Stress and Strain, sixth ed., McGraw-Hill, New York, 1989.

[34] T.R. Albrecht, S. Akamine, T.E. Carver, C.F. Quate, Microfabrication of cantilever styli for the atomic force microscope, J. Vac. Sci. Technol. A8 (1990) 3386-3396

[35] J.E. Sader, L.R. White, Theoretical-analysis of the static deflection of plates for atomic-force microscope applications, J. Appl. Phys. 74 (1993) 1-9.

[36] J.E. Sader, I. Larson, P. Mulvaney, L.R. White, Method for the calibration of atomicforce microscope cantilevers, Rev. Sci. Instrum. 66 (1995) 3789-3798.

[37] J.P. Cleveland, S. Manne, D. Bocek, P.K. Hansma, A nondestructive method for determining the spring constant of cantilevers for scanning force microscopy, Rev. Sci. Instrum. 64 (1993) 403-405.

[38] J.E. Sader, Parallel beam approximation for V-Shaped atomic-force microscope cantilevers, Rev. Sci. Instrum. 66 (1995) 4583-4587.

[39] J. Hutter, J. Bechhoefer, Calibration of atomic-force microscope tips, Rev. Sci. Instrum. 64 (1993) 1868-1873.

[40] C.A. Clifford, M.P. Seah, The determination of atomic force microscope cantilever spring constants via dimensional methods for nanomechanical analysis, Nanotechnology 16 (2005) 1666-1680.

[41] J.E. Sader, J.W.M. Chon, P. Mulvaney, Calibration of rectangular atomic force microscope cantilevers, Rev. Sci. Instrum. 70 (1999) 3967-3969.

[42] L.L. Hazel, V.V. Tsukruk, Spring constants of composite ceramic/gold cantilevers for scanning probe microscopy, Thin Solid Films 339 (1999) 249-257.

[43] J. Ralston, I. Larson, M.W. Rutland, A.A. Feiler, M. Kleijn, Atomic force microscopy and direct surface force measurements, Pure Appl. Chem. 77 (2005) 2149-2170.

[44] J.K. Eve, N. Patel, S.Y. Luk, S.J. Ebbens, C.J. Roberts, A study of single drug particle adhesion interactions using atomic force microscopy, Int. J. Pharmaceut. 238 (2002) 17-27.

[45] C.A. Clifford, M.P. Seah, Quantification issues in the identification of nanoscale regions of homopolymers using modulus measurement via AFM nanoindentation, Appl. Surf. Sci. 252 (2005) 1915-1933.

[46] S.L. Sedin, K.L. Rowlen, Adhesion forces measured by atomic force microscopy in humid air, Anal. Chem. 72 (2000) 2183-2189.

[47] B. Capella, P. Baschieri, C. Frediani, P. Miccoli, C. Ascoli, Force-distance curves by AFM. A powerful technique for studying surface interactions, IEEE Eng. Med. Biol. 16 (1997) 58-65.

[48] P. Hinterdorfer, H.J. Gruber, F. Kienberger, G. Kada, C. Riener, C. Borken, H. Schindler, Surface attachment of ligands and receptors for molecular recognition force microscopy, Coll. Surf. B: Biointerfaces 23 (2002) 115-123.

[49] M. Yu, A. Ivanisevic, Encapsulated cells: an atomic force microscopy study, Biomaterials 25 (2004) 3655-3662.

[50] J. Gu, Z. Xiao, C. Yam, G. Qin, M. Deluge, S. Boutet, C. Cai, Attaching single biomolecules selectively to the apex of AFM tips for measuring specific interactions, J. Biophys. 89 (2005) L31-L33.

[51] L. Sirghi, O. Kylian, D. Gilliland, G. Ceccone, F. Rossi, Cleaning and hydrophilization of atomic force microscopy silicon probes, J. Phys. Chem. 110 (2006) 25975-25981.

[52] T. Smith, The hydrophilic nature of a clean gold surface, J. Colloid Interface Sci. 75 (1980) 51-55.

[53] R.K. Smith, P.A. Lewis, P.S. Weiss, Patterning self-assembled monolayers, Prog. Surf. Sci. 75 (2004) 1-68. 
[54] B. Cappella, P. Baschieri, C. Frediani, P. Miccoli, C. Ascoli, Force-distance curves by AFM. A powerful technique for studying surface interactions, IEEE Eng. Med. Biol. 16 (1997) 58-65.

[55] J. Tsibouklis, M. Petty, C. Pearson, Y.P. Song, J. Warren, J. Yarwood, M.C. Petty, W.J. Feast, Pentacosa-10,12-diynoic acid/heneicosa-2,4-diyne amine alternate-layer Langmuir-Blodgett films: synthesis, polymerisation and electrical properties, J. Mater. Chem. 3 (1993) 97-104.

[56] M. Petty, J. Tsibouklis, Y.P. Song, J. Yarwood, M.C. Petty, W.J. Feast, 22-Tricosenoic acid/1-docosylamine alternate-layer Langmuir-Blodgett films: polymerisation, pyroelectric properties and infrared spectroscopic studies, J. Mater. Chem. 2 (1992) 87-91.

[57] Y.P. Song, M.C. Petty, J. Yarwood, W.J. Feast, J. Tsibouklis, S. Mukherjee, Fouriertransform infrared studies of molecular ordering and interactions in LangmuirBlodgett films containing nitrostilbene and stearic acid, Langmuir 8 (1992) 262266.

[58] Y.P. Song, J. Yarwood, J. Tsibouklis, W.J. Feast, J. Cresswell, M.C. Petty, FT infrared spectroscopic studies of alternate-layer Langmuir-Blodgett films with nonlinear optical properties, Langmuir 8 (1992) 257-261. 